\title{
Stability of insulin-induced gastric secretion after vagotomy
}

\author{
R. G. FABER, J. V. PARKIN, P. WHITFIELD, AND M. HOBSLEY \\ From the Department of Surgical Studies, The Middlesex Hospital, London
}

SUMMARY Gastric secretory response to insulin-induced hypoglycaemia was studied in 21 subjects following vagotomy and a drainage procedure for duodenal ulcer. Eighteen subjects had one early test, ie, within one month of operation, and at least one late test, ie, six months or more after operation. Seven subjects had at least two late tests.

When the insulin test results were expressed in terms of their Hollander status, there was as much variability with time as expected from previous reports. However, when results were expressed in terms of new criteria, described in the previous paper, the insulin status of postvagotomy patients remained constant with time.

In 1968 Mason and Giles reported that, when insulin tests were performed in the immediate postoperative period and again later, a proportion of patients with initially negative tests by Hollander's criteria (1948) had positive tests on the second occasion. Since then there has been general agreement that a high proportion of tests, initially negative, convert to positive at a later date, and that early tests are of relatively little value in indicating the liability to recurrent ulcer (Connell, 1973).

In the previous paper (Faber, Russell, Parkin, Whitfield, and Hobsley, 1974), we have described new criteria for interpreting the insulin test after vagotomy; these criteria divided patients into those with a $50 \%$ liability to recurrent ulcer and those with a zero liability to recurrent ulcer. In the present paper we have examined the postoperative insulin tests of those patients who had been tested on at least two occasions; the results of each test are expressed as the Hollander status, as peak acid output (PAO), and as the peak volume of gastric juice corrected for pyloric loss and duodenal reflux $\left(\mathrm{V}_{\mathrm{G}}\right)$.

\section{Patients and Methods}

Studies were performed on 21 subjects (16 men included in the previous paper and five women) following vagotomy (15 truncal, six selective) and a drainage procedure for duodenal ulcer. In 18 subjects (table I) the first test was performed within the first month of operation (early), and the

Received for publication 27 January 1975. second test at least six months after operation (late). In seven subjects (table II) two late tests were performed, the first at least one year and the second at least two years after operation. Six subjects had three tests performed, three of whom had one early and two late tests, and three of whom had three late tests. The clinical course of the patients was closely observed, particularly with reference to recurrent ulceration.

The conduct of the insulin tests and the examination of the gastric juice was exactly as described in the previous paper. In every test peak acid output (PAO) was calculated as a sum of the acid outputs of the three consecutive samples whose acid output was greatest, and multiplied by 2 so as to be expressed as $\mathrm{mmol} /$ hour. In those tests in which phenol red had been used to quantify pyloric loss, peak $V_{G}$, the volume of gastric juice corrected for pyloric loss and duodenal reflux, was similarly calculated.

\section{Results}

Four patients (three men and one woman) developed a recurrent peptic ulcer during this study. The diagnosis was made by gastroduodenoscopy in one man (patient M.H.), and at operation in the other three patients.

EARLY AND LATE TESTS

Peak acid output in response to insulin-induced hypoglycaemia in those subjects having an early and a late test is shown in table $I$, together with the Hollander status of each test. Fourteen subjects had 


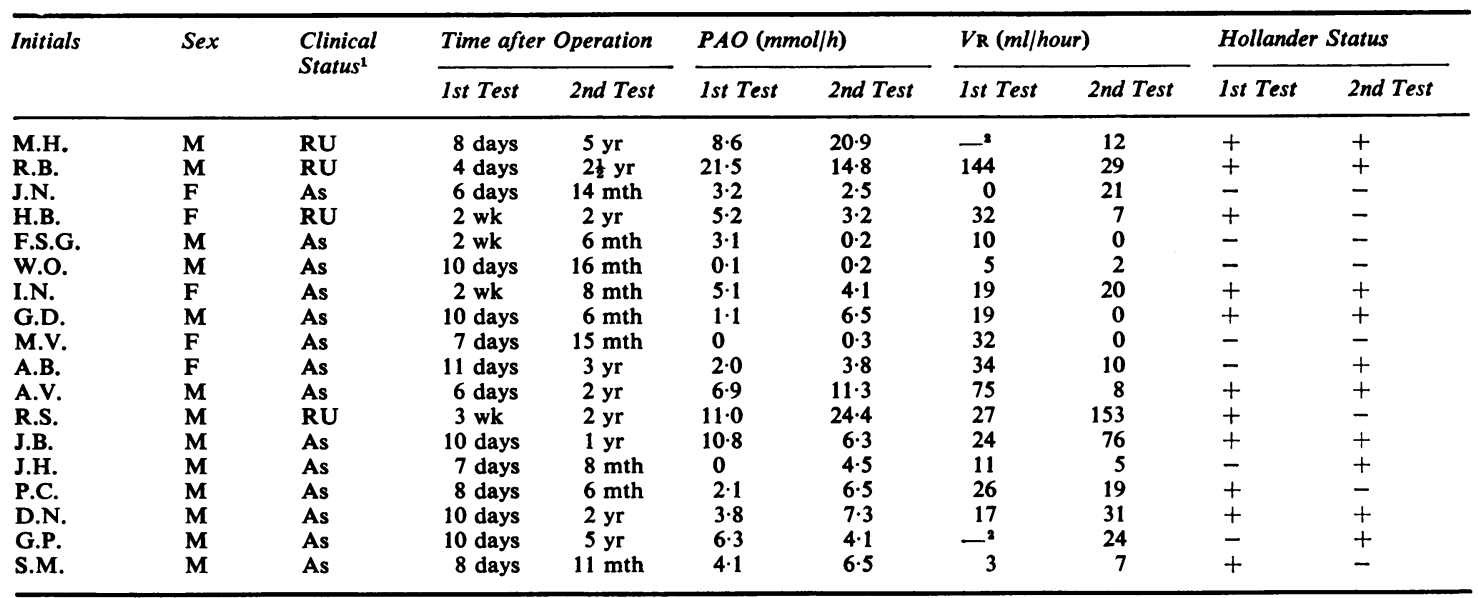

Table I Insulin test results in patients having an early and a late test

${ }^{\mathbf{2}} \mathbf{R U}=$ Recurrent ulcer, As = Asymptomatic

${ }^{2}\left[\mathrm{Na}^{+}\right]$not estimated during first test of M.H. and G.P., preventing the calculation of duodenal reflux

\begin{tabular}{|c|c|c|c|c|c|c|c|c|}
\hline \multirow[t]{2}{*}{ Initials } & \multirow[t]{2}{*}{$\operatorname{Sex}$} & \multirow[t]{2}{*}{ Clinical Status } & \multicolumn{2}{|c|}{ Time after Operation } & \multicolumn{2}{|c|}{$P A O$ (mmol/hour) } & \multicolumn{2}{|c|}{ Hollander Status } \\
\hline & & & lst Test & 2nd Test & 1st Test & 2nd Test & Ist Test & 2nd Test \\
\hline
\end{tabular}

Table II Insulin test results in patients having two late tests

a PAO less than $8 \mathrm{mmol} /$ hour, ie, free from the liability to recurrent ulcer (see previous paper), in the early test; in the late test PAO remained less than $8 \mathrm{mmol} /$ hour in 13 and was greater than $8 \mathrm{mmol} /$ hour in one. Of the four subjects secreting more than $8 \mathrm{mmol} /$ hour on the first occasion, three continued to do so on the second occasion, while one secreted less than $8 \mathrm{mmol} /$ hour. Thus in terms of the new criteria the insulin status remained remarkably constant between the early and late tests. By contrast, in terms of Hollander's criteria, of 11 initially positive tests eight remained positive and three became negative, and of seven initially negative tests four remained negative and three became positive.

The tests of the two subjects, A.V. and J.B., whose status in terms of PAO changed, were examined in more detail. The volumes of duodenal reflux (table I) in the first test of A.V. and in the second test of J.B. were sufficiently large to cause marked reduction in acid output, by neutralization. Conversely the reflux during the second test of A.V. was minimal, and in the first test of J.B. considerably less than in his second test. In both subjects phenol red had been used during the late tests, and peak $V_{G}$ was $99 \mathrm{ml} /$ hour for A.V. and $113 \mathrm{ml} /$ hour for J.B., both figures being less than $140 \mathrm{ml} /$ hour, ie, free from the liability to recurrent ulcer (see previous paper). Thus when allowance was made for duodenal reflux, there was complete stability of insulin status between early and late tests.

All three male subjects, M.H., R.B., and R.S., who secreted more than $8 \mathrm{mmol} /$ hour on both occasions, developed recurrent ulcers. The fourth subject with a recurrent ulcer, H.B., a female, secreted less than $8 \mathrm{mmol} / \mathrm{hour}$ on both occasions, and the significance of this finding will be examined in the discussion.

No significant difference could be demonstrated between PAO in the early and late tests $(P>0 \cdot 1$, Wilcoxon test for paired observations). Calculated reflux $\left(V_{R}\right)$ during peak insulin-stimulated secretion is shown in table $I$. There was considerable variation in reflux but again no trend was found between the early and late tests $(P>0 \cdot 1$, Wilcoxon test for paired observations). 


\begin{tabular}{|c|c|c|c|c|c|c|c|c|}
\hline \multirow[t]{2}{*}{ Initials } & \multirow[t]{2}{*}{$\operatorname{Sex}$} & \multirow[t]{2}{*}{ Clinical Status } & \multicolumn{2}{|c|}{ Time after Operation } & \multicolumn{2}{|l|}{ Peak $V_{G}$} & \multicolumn{2}{|c|}{ Hollander Status } \\
\hline & & & 1st Test & 2nd Test & Ist Test & 2nd Test & Ist Test & 2nd Test \\
\hline
\end{tabular}

Table III Insulin test results in patients for whom phenol red was used on two occasions

MORE THAN ONE LATE TEST

The insulin-stimulated PAO in seven subjects having two late tests is tabulated in table II together with the Hollander status for each test. One patient had a PAO in excess of $8 \mathrm{mmol} /$ hour on both occasions, and all other subjects secreted less than $8 \mathrm{mmol} / \mathrm{hour}$ on both occasions. Of the three Hollander-positive tests on the first occasion, one remained positive and two became negative; of the four initially negative Hollander tests, three remained negative and one became positive.

Three of these seven subjects (W.O., G.J., and R.W.) had three late tests, and all secreted less than $8 \mathrm{mmol} /$ hour on every occasion.

\section{GASTRIC SECRETION CORRECTED FOR}

PYLORIC LOSS AND DUODENAL REFLUX-V $\mathbf{V}_{\mathbf{G}}$ In only nine subjects was phenol red used in two separate studies, and the results are shown in table III. One subject, R.B., had peak $V_{G}$ more than 140 $\mathrm{ml} /$ hour on both occasions; all the other subjects secreted less than $140 \mathrm{ml} /$ hour on both occasions. In six of the nine subjects peak $V_{G}$ was slightly larger on the second occasion, but the difference was not statistically significant $(P>0 \cdot 1$, Wilcoxon test for paired observations). By Hollander's criteria, of five initially positive tests, three became negative and two remained positive on the second occasion: of four initially negative tests, two remained negative and two converted to positive.

Three of the nine subjects (M.V., G.J., and R.W.) had three tests carried out with phenol red, and all secreted less than $140 \mathrm{ml} /$ hour on every occasion.

\section{Discussion}

The suggestion that insulin-secretory status after vagotomy might change was made by Weinstein, Hollander, Lauber, and Colp (1950) only two years after Hollander's definitive description of his criteria for interpreting the insulin test (Hollander, 1948). They reported the results of insulin tests in 28 patients who had studies performed at less than two weeks and again at more than three months after vagotomy, and found that of 16 patients with initially negative tests five had positive tests on the second occasion.

This report seems to have escaped notice in Britain and the stability of the insulin test was not questioned until Mason and Giles (1968) described their findings in 38 patients who had a maximal acid output in excess of $20 \mathrm{mmol} /$ hour after vagotomy. They found that only 14 had positive tests by Hollander's criteria, and when 19 of the remaining 24 Hollandernegative subjects were re-tested after six months, 12 had converted to positive. In a further study (Mason and Giles, 1969) of patients secreting less than 20 mmol/hour, five patients out of 17 with initially negative tests converted to positive and two out of 26 with initially positive tests converted to negative. Gillespie, Elder, Gillespie, Kay, and Campbell (1970) stated that more than $50 \%$ of patients with initially negative Hollander tests converted to positive in a three-month to four-year follow up, and two of the 17 converters developed recurrent ulcers. Smith, Gillespie, Elder, Gillespie, and Kay (1972) tested 52 patients, all initially Hollander-negative, at twomonthly intervals for one year, and found that 21 converted to Hollander-positive. They stated that this was due to a significant increase in stimulated acid output, and that there was no change in basal secretion. They suggested three possible explanations for this change: (1) decreased duodenal reflux on subsequent testing, (2) recovered nerve function, and (3) gastric stasis at the time of the first test.

All these authors were describing changes in insulin status in terms of Hollander's criteria, which poorly predict the liability to recurrent ulcer. Change in Hollander status is probably irrelevant to the clinical situation. The new criteria (see previous paper) allow postvagotomy male subjects to be divided into those whose insulin-stimulated secretion lies within the range for unoperated duodenal ulcer subjects, and those whose secretion is less 
than the lower limit of the unoperated range. The former have a $50 \%$ liability to recurrent ulcer and the latter a zero liability, the most accurate indices of measurement being peak $\mathrm{V}_{\mathrm{G}}$ and PAO which have been used in this paper.

Using PAO, we have shown that only two out of 18 subjects changed status from an early to a late test. Moreover the changes in these two patients were explicable in terms of changes in the volume of duodenal reflux $\left(V_{R}\right)$, for, when secretion was expressed in terms of $V_{G}$, both patients fell into the recurrence-free group. However, it should be emphasized that a change in PAO from the first to the second test was not inevitably due to a change in the volume of duodenal reflux, and no correlation was obtained between these values. Such change could just as easily be due to a change in pyloric losses, and this is one of the reasons why it was necessary to reduce the lower tolerance limits of the preoperative group from $95 \%$ to $99 \%$ (see previous paper).

Overall, we were unable to show any trend towards increased acid output with time, in contradistinction to Smith et al (1972) and Kronberg (1971). Likewise we were unable to show a trend towards less duodenal reflux with time, one of the possible explanations put forward by Smith et al to explain their findings. However, it must be remembered that they were only re-testing patients with initially negative Hollander tests, and thus the only trend possible would have been towards less reflux and increased acid output. Their results might very well have been different if they had included 52 patients, initially Hollanderpositive, in their series of repeated tests. Watkin and Duthie (1971) were also unable to detect an increase in the PAO of asymptomatic subjects, but they stated that there was a significant increase in insulinstimulated secretion with time in male patients who developed recurrent ulcers. Kronberg (1971) also found an increased volume, acidity, and acid output in male patients with recurrent ulcer tested three to four years after the initial postoperative study. However, his female patients with recurrent ulceration only showed an increase in volume and not acidity or acid output. There are too few patients with recurrent ulcer in the present series to confirm or refute this report but their clinical importance is doubtful since all our male patients with recurrent ulcer secreted more than $8 \mathrm{mmol} /$ hour both on the first and on second occasions. The insulin test did not predict the recurrent ulcer in one female patient, H.B., and this finding strengthens our reservation in the previous paper that our interpretation of the insulin test can only be applied to male patients.

The results of those few patients having two or three late tests suggest that their PAO status remains constant, which is in agreement with the findings of Lyndon, Greenall, and Johnston (1974), between early and late tests. In terms of peak $\mathrm{V}_{\mathrm{G}}$, the most accurate measurement of secretion, but available in only nine patients in our series, there were no patients in whom the insulin status changed with time. There was a very slight (mean $12 \mathrm{ml}$ ), but insignificant, increase in $V_{G}$ with time, and it is possible that when more data are available a significant trend might be revealed.

We would be very interested in the results of other workers applying our criteria to their data. Several centres may have large numbers of repeated insulin tests, with peak acid output data, if not $V_{G}$.

\section{References}

Connell, A. M. (1973). Clinical Tests of Gastric Function, p. 73. Pitman, London.

Faber, R. G., Russell, R. C. G., Parkin, J. V., Whitfield, P., and Hobsley, M. (1974). The predictive accuracy of the postvagotomy insulin test: a new interpretation. Gut, 16, 337-342.

Gillespie, G., Elder, J. B., Gillespie, I. E., Kay, A. W., and Campbell, E. H. G. (1970). The long term stability of the insulin test. Gastroenterology, 58, 625-632.

Hollander, F. (1948). Laboratory procedures in the study of vagotomy (with particular reference to the insulin test). Gastroenterology, 11, 419-425.

Kronberg, O. (1971). The stability of the insulin test result after truncal vagotomy and drainage for duodenal ulcer. Scand.J. Gastroent., 6, 637-644.

Lyndon, P. J., Greenall, M. J., and Johnston, D. (1974). The secretory status of patients 4-5 years after highly selective vagotomy for duodenal ulcer. (Abstr.) Brit. J. Surg., 61, 913.

Mason, M. C., and Giles, G. R. (1968). The post-operative insulin test : failure to detect incomplete vagotomy in patients with high acid levels. (Abstr.) Brit. J. Surg., 55, 865.

Mason, M. C., and Giles, G. R. (1969). The post-operative insulin test : a further assessment. (Abstr.) Brit. J. Surg., 56, 384.

Smith, I. S., Gillespie, G., Elder, J. B., Gillespie, I. E., and Kay, A. W. (1972). Time of conversion of insulin response after vagotomy. Gastroenterology, 62, 912-917.

Watkin, D. F. L., and Duthie, H. L. (1971). Changes in the postoperative insulin test in relation to duodenal ulceration. Gut, 12, 303-310.

Weinstein, V. A., Hollander, F., Lauber, F. U., and Colp, R. (1950). Correlation of insulin test studies and clinical results in a serics of peptic ulcer cases treated by vagotomy. Gastroenterology, 14, 214-227. 